\title{
TOXICITY OF SAPONIN ISOLATED FROM Gymnema sylvestre R. BR. (ASCLEPIADACEAE) AGAINST Culex tritaeniorhynchus GILES (DIPTERA: CULICIDAE) JAPANESE ENCEPHALITIS VECTOR MOSQUITO IN INDIA
}

\author{
Kupppusamy ELUMALAI(1), Shanmugan DHANASEKARAN(2) \& Kaliamoorthy KRISHNAPPA(2)
}

\begin{abstract}
SUMMARY
To determine the larvicidal activity of various extracts of Gymnema sylvestre against the Japanese Encephalitis vector, Culex tritaeniorynchus in Tamilnadu, India. To identify the active principle present in the promising fraction obtained in Chlorofom:Methanol extract of Fraction 2. The G. sylvestre leaf extracts were tested, employing WHO procedure against fourth instar larvae of $C$. tritaeniorhynchus and the larval mortalities were recorded at various concentrations $(6.25,12.5,25.0,50 \mathrm{and} 100 \mu \mathrm{g} / \mathrm{mL})$; the $24 \mathrm{~h} \mathrm{LC}$. values of the G. Sylvestre leaf extracts were determined following Probit analysis. It was noteworthy that treatment level $100 \mu \mathrm{g} / \mathrm{mL}$ exhibited highest mortality rates for the three different crude extracts and was significantly different from the mean mortalities recorded for the other concentrations. The $\mathrm{LC}_{50}$ values of $34.756 \mu \mathrm{g} / \mathrm{mL}(24.475-51.41), 31.351 \mu \mathrm{g} / \mathrm{mL}(20.634-47.043)$ and 28.577 $\mu \mathrm{g} / \mathrm{mL}$ (25.159-32.308) were calculated for acetone, chloroform and methanol extract with the chi-square values of 10.301, 31.351 and 4.093 respectively. The present investigation proved that $G$. Sylvestre could be possibly utilized as an important component in the Vector Control Program.
\end{abstract}

KEYWORDS: Gymnema sylvestre; Culex tritaeniorhynchus; Larvicidal acitivity; Saponin.

\section{INTRODUCTION}

Mosquitoes are vectors of many different disease agents around the world. Depending on the species, mosquitoes are vectors of protozoa (e.g Plasmodium species) that cause malaria, the nematode worms that cause filariasis (e.g Wuchereria brugia) and a large number of arboviruses (e.g. yellow fever and dengue viruses) including two of great impact in the tropical and subtropical regions (i.e. yellow fever and dengue viruses). SERVICE (1990) recorded two million people primarily in tropical countries as being at risk from mosquito-borne diseases. Though, mosquito-borne diseases currently represent a greater health problem in tropical and subtropical climates, no part of the world is immune to this risk (FRADIN \& DAY, 2002). Control of mosquitoborne diseases is becoming increasingly difficult because of increasing resistance of mosquitoes to pesticides (RANSON et al., 2001). However, the discovery of the insecticide Dichloro - diphenyl - trichloroethane (DDT) in the 1940s was a major breakthrough in the control of vector borne diseases. The insecticide was highly effective for killing indoor resting mosquitoes when it was sprayed on the walls of houses. Moreover, it was cheap to produce and active over a period of time.

The application of these chemical insecticides, which have been in use for decades, has come across tremendous setbacks in the light of the development of vector resistance and some attendant environmental hazards. DON-PEDRO \& ADEGBITE (1995) showed the ease with which resistance develops in their study in the health center and surroundings of the University of Lagos, where despite spraying Dichlovos insecticides on a two weekly basis for four years, a high mosquito population still persisted. In addition, DON-PEDRO (1976) reported other deleterious effects of insecticides on non-target organisms. With these problems in focus, it becomes increasingly necessary to search for an alternative in the development of environmentally safe, biodegradable, low cost, indigenous methods for mosquito control which can be used with minimum care by individuals and communities in specific situations. This work aims to determine the efficacy of Gymnema sylvestre acetone, chloroform and methanolic leaf extracts on Culex tritaeniorynchus.

Culex tritaeniorhynchus is a vector of Japanese encephalitis (BRAM, 1967). A human orbivirus has also been isolated from this species in China (ATTOUI et al., 2005). Isolates of Getah, Sindbis, Tembusu and dengue virus have also been found in this species (LEE et al., 1989). Larvae are found in many temporary, semi-permanent and permanent ground water habitats such as rice paddies, streams, swamps, shallow marshes, low salinity tidal marshes, ponds, wells, ditches, puddles containing fresh or slightly polluted water (LEE et al., 1989). In southern India this species is predominantly collected resting outdoors (DAS et al., 2004). 


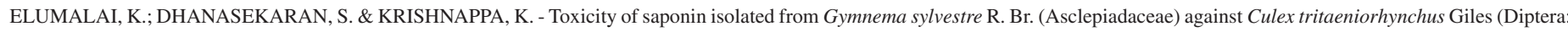
Culicidae) Japanese encephalitis vector mosquito in India. Rev. Inst.Med. Trop. Sao Paulo, 54(6): 337-44, 2012.

However, it has been found occurring in unusually high numbers resting indoors during the day time (KANOJIA \& GEEVARGHESE, 2004). C. Tritaeniorhynchus bites throughout the night with minor peaks in activity at $9 \mathrm{pm}$ and $2.30 \mathrm{pm}$ (LEE et al., 1989). Females have preference cattle and pigs, but will also occasionally feed on birds and humans (BRAM, 1967). In India, it was observed to predominantly feed on cattle, to a lesser extent on humans (ARUNACHALAM et al., 2005). Multiple feeding from two to three distinct hosts was observed during this study.

G. sylvestre, rooting at nodes, leaves elliptic, acuminate, base acute to acuminate, glabrous above sparsely or densely tomentose beneath; Flowers small, in axillary and lateral umbel like cymes, pedicels long; Calyx-lobes long, ovate, obtuse, pubescent; Corolla pale yellow campanulate, valvate, corona single, with five fleshy scales. Scales adnate to throat of corolla tube between lobes; Anther connective produced into a membranous tip, pollinia 2, erect, carpels 2, unilocular; locules many ovuled; Follicle long, fusiform.

Vector control is facing a threat due to the emergence of resistance to synthetic insecticides. Insecticides of botanical origin may serve as suitable alternative biocontrol techniques in the future. Although several plants have been reported for mosquitocidal activity, only a few botanicals have moved from the laboratory to field use, because they are poorly characterized, in most cases active principals are not determined and most of the works are restricted to preliminary screening. G. sylvestre is large climbers, common flora distributed in many parts of India with medicinal properties, but the larvicidal activity of this plant against the important Japanese Encephalitis vector, C. trataeniorynchus has not been reported so far. Hence, the present study was undertaken.

\section{MATERIALS AND METHODS}

1. Extraction procedure: The plant G. sylvestre was collected from the foothills of Western Ghats (which are considered as rich in floral diversity that comprises of mostly medicinal plants; used in traditional medicine by the inhabitant tribal communities) in Theni District, Tamilnadu, India during January - March on frequent field visit. The leaves first washed with running tap water and then shade dried on blotting paper at room temperature $\left(28 \pm 2^{\circ} \mathrm{C}\right)$ for seven days. Then the dried leaves were powdered by an electrical blender. The powder was sieved with the help of fine mesh then it was sequentially extracted in Soxhlet apparatus with acetone, chloroform and methanol individually by adapting standard method (VOGEL \& TATCHELL, 1978). The plant material (one Kg) was loaded in the inner tube of the Soxhlet apparatus and then fitted into a round bottomed flask containing acetone. The solvent was boiled gently $\left(40{ }^{\circ} \mathrm{C}\right)$ by heating the mantle using the adjustable rheostat. The extraction was continued until complete extraction was achieved and the solvent in the flask was removed then substantially filled with chloroform then methanol individually. The crude extracts were then condensed with the help of rotary vacuum evaporator to yield residue (acetone - $10.25 \mathrm{~g}$; chloroform - $8.50 \mathrm{~g}$ and methanol - $5.25 \mathrm{~g}$ ).

2. Larval rearing: The mosquito larvae were recruited from the egg colony held at the Unit of Vector control and Phytochemical Research, Department of Zoology, Annamalai University, Annamalainagar, Tamilnadu, India, where they were reared in the laboratory. The eggs were washed with $0.01 \%$ formaldehyde solution for 30 - 40 minutes as recommended by AL - MASHHADANI et al. (1980). This is necessary as a precaution against possible microsporidian infections which might interfere with the normal development of the immature stages of mosquitoes (ANOSIKE \& ONWULIRI, 1992) and soaked in water to facilitate hatching. After hatching, first instar larvae were distributed in bowls $30 \mathrm{~cm}$ in diameter and $12.5 \mathrm{~m}$ in depth. Care was taken to prevent overcrowding until development to early $4^{\text {th }}$ instar larvae required for the study. The larvae were kept in the plastic buckets half filled with tap water and fed with dog biscuit once a day initially and twice during the later stages of development. Water in rearing container was refreshed every day by removing a little quantity of water from the rearing buckets and replacing with fresh water. This was aimed at preventing scum from forming on the water surface.

\section{Bioassay}

3.1 Larvicidal bioassay: Standard methods for testing the susceptibility of mosquito larvae to insecticides as stipulated by WHO (1996) were followed. The bioassay were performed at a room temperature of $28 \pm 2{ }^{\circ} \mathrm{C}$, relative humidity $75-85 \%$, Photoperiod 12:12 (light: dark) and $\mathrm{p}^{\mathrm{H}} 7.0$ of distilled water. Twenty five (25) larvae selected by means of a rubber pipette were placed in four small separate specimen bottles containing $25 \mathrm{~mL}$ distilled water, and then exposed to each of the concentrations of the extracts in a final volume of $245 \mathrm{~mL}$ distilled water taken in $500 \mathrm{~mL}$ plastic bowls. This is done by tripping the contents of smaller specimen bottles into the $500 \mathrm{~mL}$ plastic bowls. The larvae in all the bowls were fed every twenty four hours on equal amount of dog biscuit which was spread evenly across the water surface.

Five replicates for each of the test concentration and control (without plant extracts) were tested for larvicidal effects. The larval mortalities were recorded at intervals of 12 hours. Dead larvae were identified when they failed to move after probing with a needle in the siphon or cervical region. Similar types of bioassay were conducted with different solvent extracts (concentrations of $6.25,12.5,25,50$, and $100 \mu \mathrm{g} / \mathrm{mL}$ ) of the G. sylvestre fourth instar larval forms. Larval toxicity was also tested according to similar methodologies using the bioactive substances (from chloroform:methanol extract) isolated from thin-layer chromatographic (TLC) plates.

4. Phytochemical analysis: The presence of phytochemicals was determined using the method described by HARBORNE (1984) and EVANS (2002) with slight modifications. One or two drops of the chloroform:methanol extract were applied (using a capillary tube) to the bottom of each of the pre-coated and pre-heated $\left(100{ }^{\circ} \mathrm{C}\right.$ for 30 minutes $)$ glass plates (eight glass plates), which were prepared with silica gel G using Unoplan coating apparatus (Shadon, London). After five minutes of drying, each of the plates was placed in the separate glass chamber for TLC analysis, with different solvent systems as the mobile phase. After the movement of solvent at the top of the plates, each plate was removed from the glass chamber and separately air-dried. After 10 minutes each of plates was sprayed with a different spraying reagent for the identification of appropriate phytochemical. The phytochemicals included in the study were sapogenins, steroid, terpenoids, flavonoids, alkaloid, essential oils, phenolics and amino acids. A qualitative test was carried out to indicate the presence of saponins (KOKATE, 1999); the remaining phytochemicals were determined using TLC analysis by the application of suitable solvents and spray reagents and, in each case, $R_{\mathrm{f}}$ values were recorded. 


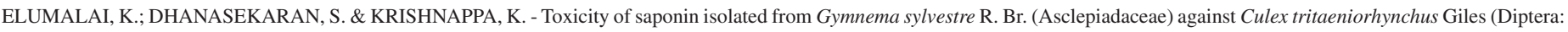
Culicidae) Japanese encephalitis vector mosquito in India. Rev. Inst.Med. Trop. Sao Paulo, 54(6): 337-44, 2012.

5. Ultraviolet-visual and infrared analysis of the active ingredient: The chloroform:methanol extract of the leaves of $G$. sylvestre was further chromatographed (30 plates) without the application of spraying reagents and each of the spots showed positive activity were separately scrapped according to their respective $R_{\mathrm{f}}$ values. Then each of the spots with their distinguishing $\mathrm{R}_{\mathrm{f}}$ value was combined (from 30 plates) and undergoes further bioassay experiment to reveal the nature of active ingredient. As the spots exhibited positive response in Liberman Buchard reagent recorded highest larval mortality during further bioassay experiments, it undergoes spectral analysis by ultraviolet-visual (UV-Vis) and infrared (IR) spectroscopy. The UV-Vis analysis was carried out using a UV1601 PC, SHIMADZU spectrophotometer with medium scan speed and sampling interval of 0.5 seconds. The IR spectroscopy analysis of the active spot was performed using KBr plates (JASCO FT-IR Model-420) with a scanning speed of $2 \mathrm{~mm} \mathrm{~s}^{-1}$. All solvents and reagents used were of analytical grade and purchased from E. Merck, India. The TLC silica gel plates $(0.25 \mathrm{~mm}$ thickness $)$ were prepared and equilibrated with $2 \%$ (w/w) of water before use.

6. Statistical analysis: All the mortalities were counted and recorded as in percentages. The percentage mortality observed $(\% \mathrm{M})$ was corrected using Abbott's formula (ABBOTT, 1925) during the observation of the larvicidal potentiality of the plant extracts. Probit analysis (FINNEY, 1971) was used to determine the median lethal concentration $\mathrm{LC}_{50}$ (WOOLF, 1968, WARDLAW, 2002). A 3 X 5 Factorial experiment in completely randomized block design analysis of variance (ANOVA) was performed.
Duncan Multiple Range Test (DMRT) was used to separate the means of the main factors (plant extract, concentration and their interactions).

\section{RESULT}

1. Larvicidal activity: The efficacy of acetone extract of $G$. sylvestre on fourth instar larvae of Culex tritaeniorhynchus is presented in Table 1. The larvicidal effect of the plant extract was clearly dependent on the concentrations of the extract. All the larvae maintained in the control medium survived for $24 \mathrm{hrs}$, thus no mortality was observed among the control batch larvae. The experimental larvae were more susceptible to the maximum concentration hence, the maximum larval mortality of $100.00 \%$ was observed in $100 \mathrm{ppm}$ concentration of acetone and methanol extracts. DMRT analysis clearly showed significant difference in the mean mortality of the larvae among the various treatment concentration of the three extracts $(\mathrm{p} \leq 0.05)$. besides, at $6.25 \mathrm{ppm}$ concentration $6.88,10.54$ and $15.38 \%$ larval mortality was observed from acetone, chloroform and methanol crude extracts of $G$. sylvestre. Larvicidal activity of 20.08, $21.75,27.92 \%$ were recorded in acetone, chloroform and methanol extracts respectively at $25.00 \mathrm{ppm}$ concentration. Similar trend was also observed from the $50.00 \mathrm{ppm}$ concentration of all the three extracts. It was noteworthy that treatment level 100 ppm exhibited highest mortality rates for the three different crude extracts and was significantly different from the mean mortalities recorded for the other concentrations. The $\mathrm{LC}_{50}$ values of $34.756 \mathrm{ppm}(24.475-51.41), 31.351 \mathrm{ppm}(20.634-47.043)$ and 28.577 ppm (25.159-32.308) were calculated in acetone, chloroform

Table 1

Lethal activities of crude extracts of Gymnema sylvestre at different concentrations against fourth instar larvae of Culex tritaeniorhynchus

\begin{tabular}{|c|c|c|c|c|c|}
\hline \multirow{2}{*}{ Concentrations tested $(\mu \mathrm{g} / \mathrm{mL})$} & \multirow{2}{*}{ Mortality (\%) } & \multirow{2}{*}{$\mathrm{LC}_{50}$} & \multicolumn{2}{|c|}{$95 \%$ Confidence limit } & \multirow{2}{*}{$\chi^{2}$ value } \\
\hline & & & Lower & Upper & \\
\hline \multicolumn{6}{|l|}{ Acetone extract } \\
\hline Control & $00.00^{\mathrm{a}}$ & & & & \\
\hline 6.25 & $6.88^{\mathrm{b}}$ & & & & \\
\hline 12.50 & $20.08^{\mathrm{d}}$ & 34.756 & 24.475 & 51.41 & 10.301 \\
\hline 25.00 & $45.17^{\mathrm{f}}$ & & & & \\
\hline 50.00 & $66.83^{\mathrm{h}}$ & & & & \\
\hline 100.00 & $100.00^{\mathrm{j}}$ & & & & \\
\hline \multicolumn{6}{|l|}{ Chloroform extract } \\
\hline Control & $00.00^{\mathrm{a}}$ & & & & \\
\hline 6.25 & $10.54^{\mathrm{b}}$ & & & & \\
\hline 12.50 & $21.75^{\mathrm{d}}$ & 31.351 & 20.634 & 47.043 & 31.351 \\
\hline 25.00 & $52.50^{\mathrm{g}}$ & & & & \\
\hline 50.00 & $73.33^{\mathrm{i}}$ & & & & \\
\hline 100.00 & $99.00^{\mathrm{j}}$ & & & & \\
\hline \multicolumn{6}{|l|}{ Methanol extract } \\
\hline Control & $00.00^{\mathrm{a}}$ & & & & \\
\hline 6.25 & $15.38^{\mathrm{c}}$ & & & & \\
\hline 12.50 & $27.92^{\mathrm{e}}$ & 28.577 & 25.159 & 32.308 & 4.093 \\
\hline 25.00 & $51.17^{\mathrm{g}}$ & & & & \\
\hline 50.00 & $75.83^{\mathrm{i}}$ & & & & \\
\hline 100.00 & $100.00^{\mathrm{j}}$ & & & & \\
\hline
\end{tabular}

Values are mean \pm SD for five replications. Values not sharing a common superscript differ significantly at $p<0.05$ (DMRT). 


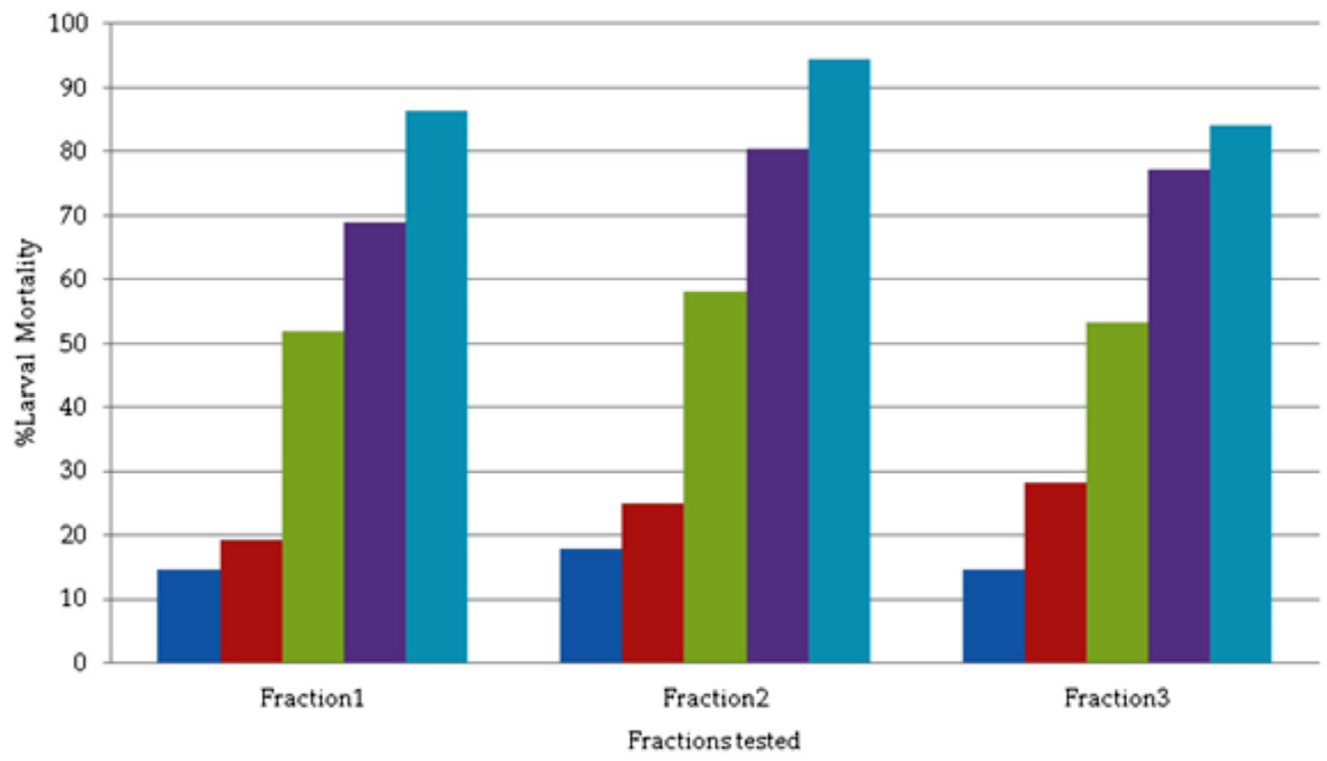

$=6.25 \mu \mathrm{g} / \mathrm{mL}=12.5 \mu \mathrm{g} / \mathrm{mL}=25 \mu \mathrm{g} / \mathrm{mL} \quad 50 \mu \mathrm{g} / \mathrm{mL}=100 \mu \mathrm{g} / \mathrm{mL}$

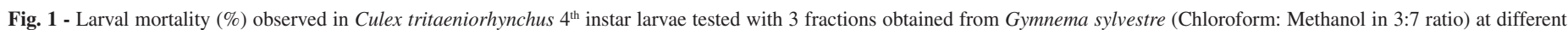
concentrations.

and methanol extract with the chi-square values of $10.301,31.351$ and 4.093 respectively (Table 1 ). In the same way the mean larval mortality obtained from various fractions were depicted in the Figure 1.

2. Phytochemical analysis: The results of preliminary phytochemical analysis of the chloroform:methanol extract of the green berries of $G$. sylvestre is shown in Table 2. A qualitative test indicated the presence of saponins and chromatographic analysis revealed the presence of steroids,

Table 2

Qualitative analysis of the phytochemicals of methanol extracts of Gymnema sylvestre tested leaves

\begin{tabular}{lc}
\hline Phytochemicals & Compounds \\
\hline Alkaloids & + \\
Carbohydrates & + \\
Saponins & + \\
Phytosteroids & + \\
Phenols & + \\
Phenols & + \\
Flavanoids & + \\
Terpenoids & - \\
Tannins & + \\
Phlobatanins & - \\
\hline
\end{tabular}

+ Presence of the phytochemical compound; - Absence of the phytochemical compound. alkaloids, terpenoids, saponins, amino acids, phenolics, flavonoids and essential oil as major phytochemicals and the absence of the sapogenins following the application of different solvent systems and spraying reagents. When the isolated compounds from the TLC plates were further bio-assayed against the fourth instar larvae, the mortality was recorded in two compounds. The highest mortality (at a concentration of $100 \mathrm{ppm}$ ) was recorded in the first compound having $R_{\mathrm{f}}=0.818$ (94.5\% in 48 hours at $100 \mathrm{ppm})$ followed by a second compound having $R_{\mathrm{f}}=0.946(84.33 \%$ in 48 hours at $50 \mathrm{ppm}$ ) with maximum absorption at 297.50 and $361.00 \mathrm{~nm}$, respectively from fraction 2 during UV-Vis analysis.

\section{DISCUSSION}

Biopesticides may serve as suitable alternative to chemical insecticides in future as they are relatively safe, inexpensive and available everywhere in the world. Nowadays, mosquito control is mostly directed against larvae and only against adults when necessary. This is because the fight against adult is temporary, unsatisfactory and polluting for the environment, while larval treatment is more localized in time and space resulting in less-dangerous outcomes. Larval control can be an effective control tool due to the low mobility of larval mosquitoes, especially where the principal breeding habitats are man-made and can be easily identified (HOWARD et al., 2007)

This work demonstrates the potency of $G$. sylvestre leaf extract as an effective larvicide against $C$. tritaeniorynchus larvae; it was highly toxic to mosquito larvae. The high rates of larval mortality observed at $100 \mathrm{ppm}$ within $48 \mathrm{hrs}$ with LC $_{50}$ value $28.577 \mathrm{ppm}$ indicate the high toxicity of the methanol leaf extract. According to MUSTAFA \& AL KHAZRAJI (2008) Azadirachta excels showed excellent larvicidal properties at low concentrations against Culex pipiens molestus. Its 
$\mathrm{LC}_{50}$ value after one day was $62.5 \mu \mathrm{g} / \mathrm{mL}$. DUA et al. (2009) stated that, emulsified concentration of neem oil formulation showed $95.5 \%$ reduction in larval population of $C$. quinquefasciatus in one day under field trails and thereafter $80 \%$ reduction was achieved up to the third week. The major bioactive constituents of Gymnema sylvestre is triterpenoid saponins (5.50\%) and tannins (1.00\%). WIESMAN et al. (2005) reported that saponin extracted from the fruit of Balanites aegyptiaca showed $100 \%$ larvicidal activity against Aedes aegypti mosquito larvae. Aqueous extract of Gymnema sylvestre causes 31, 45, 45, 71 and $100 \%$ mortality to $C$. quinquefasciatus at 1,2,3,4 and 5\% concentration respectively (KHANNA \& KANNABIRAN, 2007). Results of present study are in line with earlier work done. SHARMA et al. (2005) tested alcoholic and acetone extracts of $N$. indium leaf against Anopheles stephensi and found results of $\mathrm{LC}_{50}$ at $185.99 \mathrm{ppm}$ after 24 hours of exposure. SRIVASTAVA et al. (2003) examined the aqueous and methanolic extract of $N$. indium lattices against Culex quinquefasciatus and obtained that different dilutions of the lattices delay the post embryonic development of Culex larvae, methanolic extract is 1.8 times more toxic than aqueous extract. Datura metel showed less activity among the tested plant extracts with 54\% mortality at 5 ppm. MUSTAFA \& AL-KHAZRAJI (2008) tested the Datura stramonium seed extract against larvae of Culex pipiens at $20 \mu \mathrm{g} / \mathrm{mL}$, caused very low mortality up till seven days of exposure.

The secondary compounds of plants make up a vast repository of compounds with a wide range of biological activities. Most studies report active compounds as steroidal saponins. Saponins are freely soluble in both organic solvents and water, and they work by interacting with the cuticle membrane of the larvae, ultimately disarranging the membrane, which is the most probable reason for larval death (HOSTETTMANN et al., 1995). WIESMAN \& CHAPAGAIN (2005) reported that saponin extracted from the fruit of Balanites aegyptica showed $100 \%$ mortality against larvae of $S$. aegypti. The larvicidal property of a saponin mixture isolated from Cestrum diurnum was also evaluated against Anopheles stephensi mosquito by GHOSH \& CHANDRA (2006). Recently, KRISHNAPPA \& ELUMALAI (2012) reported that essential oil obtained from Clausena excavata exhibited strong larvicidal and ovicidal activity again Spodoptera litura. From the leaves of Duranta repens (Verbenaceae) two new triterpene saponins, named durantanin IV (1) and V (2) were isolated. In addition, ten known compounds were isolated, namely a bidesmosidic saponin, oleanolic acid, three phenylethanoids and five flavonoids. All metabolites were isolated for the first time from this genus except for three (oleanolic acid) and seven (E/Z acteoside). The structures were determined mainly by spectroscopic methods (UV, IR, HRESI-MS, ${ }^{1} \mathrm{H}-,{ }^{13} \mathrm{C}-\mathrm{NMR},{ }^{1} \mathrm{H}-{ }^{1} \mathrm{H}$ COSY, HSQC and HMBC). Cytotoxic screening of the chloroform, ethyl acetate and methanol extracts was carried out on brine shrimps.

These findings have re-emphasized the need to explore the possibility of using plant based larvicide and reduce the chemical hazards in the environment. The leaf extract of $G$. sylvestre was very promising. Furthermore, all these plant materials can be easily collected from the

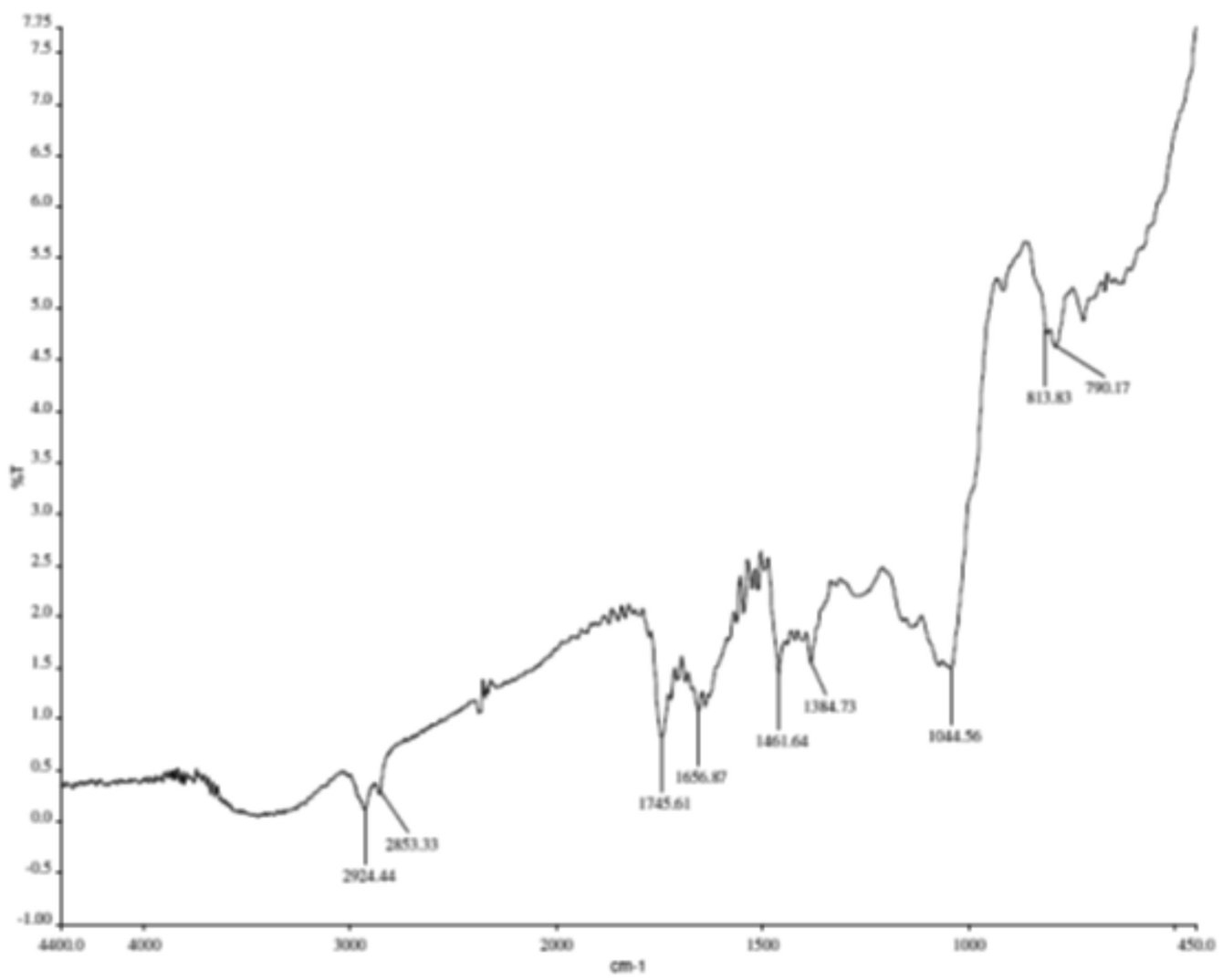

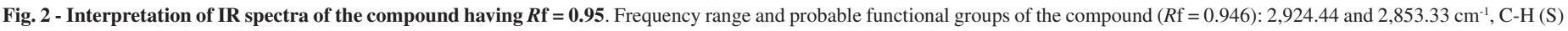

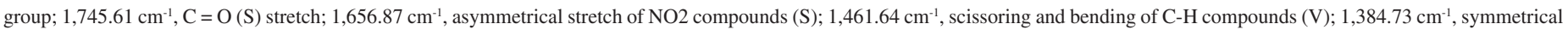

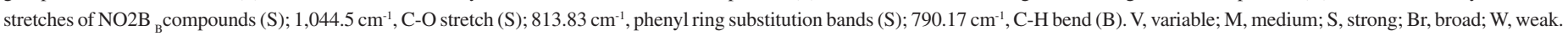




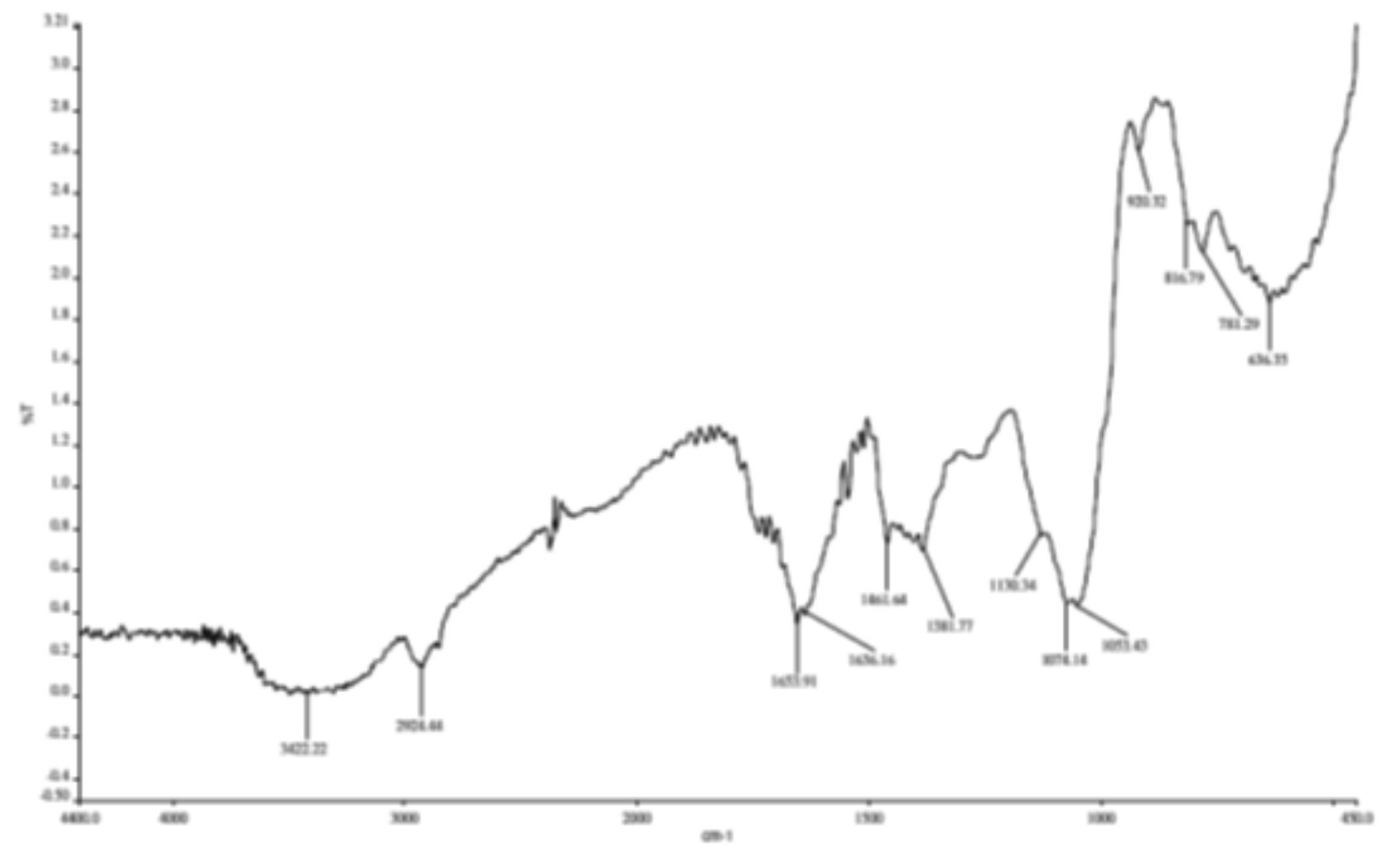

Fig. 3 - Interpretation of IR spectra of the compound having $\boldsymbol{R} \mathbf{f}=\mathbf{0 . 8 2}$. Frequency range and probable functional groups of the compound $\left(R_{\mathrm{f}}=0.818\right): 3,422.22 \mathrm{~cm}^{-1}, \mathrm{H}$ bonded $\mathrm{OH}$ stress

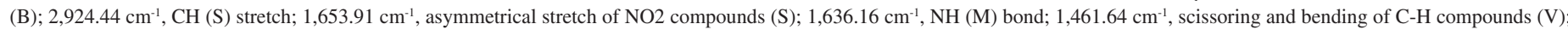
$1,381.77 \mathrm{~cm}^{-1}$, doublet isopropyl (M-W); 1,130.34, 1,074.14, 1,053.43 $\mathrm{cm}^{-1}$, CO group (S) stretch; $920.32 \mathrm{~cm}^{-1}$, alkenes (S) bend; $816.79,781.29 \mathrm{~cm}^{-1}$, CH phenyl ring (S) substitution bend; $636.35 \mathrm{~cm}^{-1}$, alkynes bend (B). V, variable; M, medium; S, strong; $\mathrm{Br}$, broad; $\mathrm{W}$, weak.

nature. Therefore, plant originated insecticides can be used as sustainable larvicide in the mosquito control program.

The present investigation revealed that the presence of several bioactive compounds in G. sylvestre. However, the IR spectra of the bioactive compounds (Fig. 2 and 3 ) during the present study also indicated that any saponin compound(s) is responsible for larval toxicity.

\section{CONCLUSION}

G. sylvestre offers promise as potential bio control agent against C. tritaeniorhynchus particularly in its markedly larvicidal effect. The extract or isolated bioactive phytochemical could be used in stagnant water bodies for the control of mosquitoes acting as vector for many communicable diseases. The extract or isolated bioactive phytochemical from the plant could be used in stagnant water bodies which are known to be the breeding grounds for mosquitoes. However, further studies on the identification of the active principals involved and their mode of action and field trials are needed to recommend G. sylvestre as an insecticidal product used to combat and protect from mosquitoes in a Vector Control Program.

\section{COMPETING INTERESTS}

The author(s) declare(s) that they have no conflict of interests.

\section{AUTHORS' CONTRIBUTIONS}

KE carried out the laboratory bioassay experimentation and phytochemical analysis of the extract. KK participated in the statistical and spectroscopic analysis and drafted the manuscript. SD participated in the conception, design of experiments, critical revision of the manuscript and coordination. All authors read and approved the final manuscript.

\section{RESUMO}

Toxicidade da saponina isolada de Gymnema sylvestre $\mathbf{R}$. BR. (ASCLEPIADACEAE) contra Culex tritaeniorhynchus Giles (Diptera: Culicidae) mosquito vetor da encefalite japonesa na Índia

O presente trabalho é para identificar a atividade larvicida de vários extratos da Gymnema sylvestre contra o vetor da encefalite japonesa, Culex tritaeniorhynchus em Tamilnadu, Índia. Com este propósito o princípio ativo presente na fração mais promissora foi obtida através de um extrato clorofórmio:metanol da fração 2. Os extratos das folhas do G. sylvestre foram testados empregando o procedimento da WHO contra estágios quaternários da larva do C. tritaeniorhynchus e as mortalidades larvais foram registradas após várias concentrações $(6,25,12,5,25,0$ e $100 ; 34,756 \mu \mathrm{g} / \mathrm{mL}(24,475-51,41), 31,351 \mu \mathrm{g} / \mathrm{mL}(20,634-47,043)$ e $28,577 \mu \mathrm{g} / \mathrm{mL}(25,159-32,308) \mathrm{g} / \mathrm{mL})$; os valores de $\mathrm{LC}_{50}$ de 24 horas dos extratos das folhas de G. sylvestre foram determinados seguindo a análise Probit. Foi notado que o nível de tratamento de $100 \mu \mathrm{g} / \mathrm{mL}$ exibiu a mortalidade mais alta para os três diferentes extratos crus e foi significantemente diferente das mortalidades médias registradas para as outras concentrações. Os valores de $\mathrm{LC}_{50}$ de $34,756 \mu \mathrm{g} / \mathrm{mL}(24,475$ $51,41), 31,351 \mu \mathrm{g} / \mathrm{mL}(20,634-47,043)$ e $28,577 \mu \mathrm{g} / \mathrm{mL}(25,159-32,308)$ foram calculados para os extratos de acetona, clorofórmio e metanol com os valores de qui-quadrado de 10,301, 31,351 e 4,093 respectivamente. A presente investigação mostra que o G. sylvestre pode ser usado como 
ELUMALAI, K.; DHANASEKARAN, S. \& KRISHNAPPA, K. - Toxicity of saponin isolated from Gymnema sylvestre R. Br. (Asclepiadaceae) against Culex tritaeniorhynchus Giles (Diptera: Culicidae) Japanese encephalitis vector mosquito in India. Rev. Inst.Med. Trop. Sao Paulo, 54(6): 337-44, 2012.

componente importante no programa de controle do vetor.

\section{ACKNOWLEDGEMENTS}

We are grateful to Professor N. Kalaichelvi, Zoology, Department of Advanced Zoology and Biotechnology, Govt. Arts College (Autonomous), Nandanam, Chennai-35 for laboratory facilities provided. Professor Dr. Govindaraju, Department of Chemistry, Kongu Polytechnique College, Erode, Tamilnadu, India, for his contribution in analysis and interpretation of data. We extend our gratitude to Dr Anbalagan, Taxonomist, Department of Botany, Annamalai University, Annamalainagar, Tamilnadu, India for the taxonomic identification of the selected plant.

\section{REFERENCES}

1. Abbott WS. A method for computing the effectiveness of an insecticide. J Econ Entomol. 1925;18:265-7.

2. Ahmed WS, Mohamed MA, El-Dib RA, Hamed MM. New triterpene saponins from Duranta repens Linn. and their cytotoxic activity. Molecules. 2009;14:1952-65.

3. Al-Mashhadani HM, Davidson G, Curtis CF. A genetic study of the susceptibility of Anopheles gambiae to Plasmodium berghei. Trans R Soc Trop Med Hyg. 1980;74:58591.

4. Amin E, El-Hawary SS, Fathy MM, Mohammed R, Ali Z, Tabanca N, et al. Triterpenoidal saponins: bioactive secondary metabolites from Zygophyllum coccineum L. Planta Med. 2011;77:488-91.

5. Anandan A, Krishnappa K, Govindarajan M, Elumalai K. Antifeedant activity of some plant extracts against the fourth instar larvae of Spodpotera litura (Hub.). Int J Rec Sci Res. 2011;2:1-3.

6. Anandan A, Krishnappa K, Mathivanan T, Elumalai K, Govindarajan M. Bioefficacy of Hyptis suaveolens and Melochia chorcorifolia against the armyworm, Spodoptera litura (Fab.) (Lepidoptera: Noctuidae). Int J Curr Res. 2010;4:117-21

7. Anosike JC, Onwuliri COE. Experimental Wuchereria bancrofti infection of Culex quinquefasciatus and Aedes aegypti. Angew Parasitol. 1992;33:139-42.

8. Arunachalam N, Samuel PP, Hiriyan J, Rajendran R, Dash AP. Observation of the multiple feeding behaviour of Culex tritaeniorhynchus (Diptera:Culicidae), the vector of Japanese encephalitis in Kerala in Southern India. Am J Trop Med Hyg. 2005; $72: 198-200$.

9. Attoui H, Mohd Jaafar F, Belhouchet M, Aldrovandi N, Tao S, Chen B, et al. Yunnan orbivirus, a new orbivirus species isolated from Culex tritaeniorhynchus mosquitoes in China. J Gen Virol. 2005;86:3409-17.

10. Bram RA. Contributions to the mosquito fauna of Southeast Asia (Diptera: Culicidae). II. The genus Culex in Thailand. Contr Am Entomol Inst. 1967;2:1-296.

11. Das BP, Lal S, Saxena VK. Outdoor resting preference of Culex tritaeniorhynchus, the vector of Japanese encephalitis in Warangal and Karim Nagar districts, Andhra Pradesh. J Vect Borne Dis. 2004;41:32-6.

12. Don-Pedro KN. The effects of insecticides on non - target anthropoids in cowpea ecosystem. [Thesis]. Ibadan: University of Ibadan; 1976

13. Don-Pedro KN, Adegbite TO. Nevan resistance in field strain of Aedes aegypti (L.) in Lagos, Nigeria. Environ Poll Ser A. 1995;38:19-29.

14. Dua VK, Pandey AC, Raghavendra K, Gupta A, Sharma T, Dash AP. Larvicidal activity of neem oil (Azadirachta indica) formulation against mosquitoes. Malaria J. $2009 ; 8,124$.
15. Elumalai K, Dhanasekaran S, Veeraiyan G, Meenakshi V. Feeding deterrent activity of certain plant extracts against the fruit borer, Helicoverpa armigera (Hubner). J Appl Zool Res. 2008;19:133-8.

16. Elumalai K, Krishnappa K, Anandan A, Govindarajan M, Mathivanan T. Antifeedant activity of medicinal plant essential oils against Spodoptera litura (Lepidoptera:Noctuidae). Int J Rec Sci Res. 2010;2:62-8.

17. Elumalai K, Krishnappa K, Anandan A, Govindarajan M, Mathivanan T. Larvicidal and ovicidal activity of seven essential oil against lepidopteran pest $S$. litura (Lepidoptera: Noctuidae). Int J Recent Sci Res. 2010;1:8-14

18. Evans WC. Trease and Evans' Pharmacognosy. $15^{\text {th }}$ ed. Edinburgh: W.B. Saunders; 2002. p. $135-50$

19. Finney DJ. Probit analysis. $3^{\text {rd }}$ ed. Cambridge: Cambridge University Press; 1971 p. 38 .

20. Fradin MS, Day JF. Comparative efficacy of insect repellents against mosquito bites N Engl J Med. 2002;347:13-8

21. Ghosh A, Chandra G. Biocontrol efficacy of Cestrum diurnum (L.) (Solanaceae Solanales) against the larval forms of Anopheles stephensi. Nat Prod Res. 2006,20:371-9.

22. Harborne JB. Phytochemical methods, a guide to modern techniques of plant analysis. London: Chapman and Hall; 1984. p. 49-188.

23. Hostettmann K, Marston A. Saponins. Cambridge: Cambridge University Press 1995. p.132.

24. Howard AF, Zhou G, Omlin FX. Malaria mosquito control using edible fish in western Kenya: preliminary findings of a controlled study. BMC Public Health. 2007;7:199.

25. Kanojia, PC, Geevarghese G. First report on high-degree endophilism in Culex tritaeniorhynchus (Diptera: Culicidae) in an area endemic for Japanese encephalitis. J Med Entomol. 2004;41:994-6.

26. Khanna V, Kannabiran K. Larvicidal effect of Hemidesmus indicus, Gymnem sylvestre, and Eclipta prostrata against Culex quinquefasciatus mosquito larvae. Afric J Biotechnol. 2007;6:307-11.

27. Kokate A. Phytochemical methods. Phytotherapy. 1999;78:126-9.

28. Krishnappa K, Anandan A, Mathivanan T, Elumalai K, Govindarajan M. Antifeedant activity of volatile oil of Tagetes patula against armyworm, Spodoptera litura (Fab.) (Lepidoptera: Noctuidae). Int J Curr Res. 2010;4:109-12.

29. Krishnappa K, Elumalai K, Anandan A, Govindarajan M, Mathivanan T. Insecticida properties of Thymus persicus essential oil and their chemical composition agains armyworm, Spodoptera litura (Fab.) (Lepidoptera: Noctuidae). Int J Rec Sci Res. 2010;8:170-6.

30. Krishnappa K, Elumalai K. Chemical composition of essential oil from Clausena excavata and its larvicidal and ovicidal activities against armyworm, Spodoptera litura (Fab.) (Lepidoptera: Noctuidae). Asian Pacific J Trop Dis. 2012;1-6.

31. Lee DJ, Hicks MM, Debenham ML, Griffiths M, Marks EN, Bryan JH, et al. The culicidae of the Australian region. Canberra: Australian Government Publishing Service; 1989. v. 7.

32. Mustafa MA, Al-Khazaraji A. Effect of some plant extracts on the Culex pipiens molestus Forskal larvae. Iraqi J Vet Sci. 2008;22:9-12.

33. Ranson H, Rossiter L, Ortelli F, Jensen B, Wang Z, Roth CW, et al. Identification of a novel class of insect glutathione. S - transferases involved in resistance to DDT in the malaria vector Anopheles gambiae. Biochem J. 2001:359:295-304. 
ELUMALAI, K.; DHANASEKARAN, S. \& KRISHNAPPA, K. - Toxicity of saponin isolated from Gymnema sylvestre R. Br. (Asclepiadaceae) against Culex tritaeniorhynchus Giles (Diptera: Culicidae) Japanese encephalitis vector mosquito in India. Rev. Inst.Med. Trop. Sao Paulo, 54(6): 337-44, 2012.

34. Service MW. Handbook to the Afrotropical Toxorhynchitine and Culicine mosquitoes, excepting Aedes and Culex. London: British Museum (Natural History); 1990.

35. Sharma P, Mohan L, Srivastava CN. Larvicidal potential of Nerium indicum and Thuja orientelis extracts against malaria and Japanese encephalitis vector. J Environ Biol. 2005;26:657-60

36. Srivastava VK, Singh SK, Rai M, Singh A. Toxicity of Nerium indicum and Euphorbia royleana lattices against Culex quinquefasciatus mosquito larvae. Nig J Nat Prod Med. 2003;7:61-4.

37. Vogel AI, Tatchell AR. Textbook of practical organic chemistry. $4^{\text {th }}$ ed. London: Longmans; 1978.

38. Wardlaw HC. Practical statistic for experimental biologists. New York: John Wiley; 2002. p. $256-68$
39. WHO. Report of WHO informal consultation on the evaluation and testing insecticides. CTD/WHO PES/IC. 1996.

40. Wiesman Z, Chapagain BP. Larvicidal effects of aqueous extracts of Balanites aegyptiaca (desert date) against the larvae of Culex pipiens mosquitoes. Afr J Biotechnol. 2005,4:1351-4

41. Woolf CM. Principles of Biometry: statistics for biologists. Princeton: Van Nostrand; 1968.

Received: 28 March 2012

Accepted: 23 May 2012 